Conclusion The significant difference between radiographic and MRI findings in detecting of vertebral fractures was found. The results suggest that plain X-rays cannot be considered as a sufficient method for detection vertebral fractures in patients with AS. MRI should be considered as the method of choice in revealing spinal fractures in AS patients. Disease activity may contribute in developing of non - traumatic spinal fractures in this group of patients.

\section{SAT0027 HIP JOINT INVOLVEMENT IN PSORIATIC ARTHRITIS (PSAR)}

CJ Michet. Department of Rheumatology, Mayo Clinic, Rochester, USA

10.1136/annrheumdis-2001.379

Background Long term studies of the spondyloarthropathies have identified early hip joint involvement as a marker for severe disease and disability. Psoriatic spondylitis (PsSp) results in hip arthroplasty more frequently than primary ankylosing spondylitis. It is not clear whether the risk for hip involvement exists only for PsSp or other variants of PsAr.

Objectives To evaluate the prevalence of hip joint involvement cohort of PsAr patients. To determine whether gender, type of psoriasis, PsAr peripheral joint pattern, age of onset of disease, presence of spondylitis are associated with the risk of hip joint involvement. To determine the frequency of hip arthroplasty in these patients.

Methods This is a retrospective cohort study of 417 patients with PsAr treated at a single tertiary academic centre over a 15 year period. Patient characteristics and outcome were abstracted by chart review. Radiographs of patients with hip joint disease were reviewed.

Results 27 PsAr patients (6.5\%) were diagnosed with hip joint involvement. $60 \%$ had biltaeral involvement. Gender, type of psoriasis, nail involvement, pattern of peripheral psoriatic arthritis, DIP joint involvement, or clinical enthesitis were not associated with hip joint disease. Sacroiliitis or spondylitis were strongly associated with hip disease $(\mathrm{p}<0.01)$, as was early age of onset of PsAr ( $p<0.001) .27 \%$ of the spondylitis patients developed hip disease. $37 \%$ of the patients with hip disease required total hip arthroplasty (THA).

Conclusion Hip joint involvement in psoriatic arthritis is strongly associated with early onset psoriatic arthritis and the presence of psoriatic spondylitis. A high risk of premature THA exists. Better strategies for early diagnosis and medical intervention are needed.

\section{SAT0028 LATE ONSET ANKYLOSING SPONDYLITIS-CLINICAL AND RADIOLOGICAL MANIFESTATIONS}

DK Kerimovic-Morina, D Jablanovic. Clinical V, Institute of Rheumatology-Belgrade, Belgrade, Yugoslavia

\subsection{6/annrheumdis-2001.380}

\section{Background}

Objectives To compare clinical and radiological manifestations of late onset ankylosing spondylitis (LOAS: $>51 \mathrm{yrs)}$ with classical onset ankylosing spondylitis (COAS:21-30 yrs).

Methods We identified twenty-nine (2,0\%) pts with LOAS out of 1434 AS pts and they were matched for sex and disease duration with COAS pts. All pts fulfilled the diagnostic criteria of AS of the European Spondyloarthropathy study group (ESSG). Evaluation included clinical examination: inflammatory pain, spinal mobility (Schober test, chest expansion), peripheral arthritis and enthesitis, acute uveitis, family history; laboratory (ESR, HLAB27); radiographs of the sacroiliac joints (SIJ), anteroposterior and lateral spine and affected peripheral joints). Statistical analysis was performed using Spearman rank correlation test and Xtest.

Results Analysis revealed no significant differences ( $\mathrm{p}>0.005$ ) in clinical manifestations between twenty-nine $(27 \mathrm{~m}, 2 \mathrm{f}) \mathrm{pts}$ with LOAS(mean age and disease duration 56,0 yrs (range 5362) and 8, o yrs (range 8-12) respectively) and twenty-nine pts with COAS(mean age at onset 24,2 yrs and mean disease duration 7,8 yrs (range 4-16) rescpectively), except for spinal mobility $(\mathrm{p}<0,005)$. No significant differences $(\mathrm{p}>0,005)$ were found between groups of the laboratory findings. All pts had bilateral sacroiliitis. The results are shown in the Table 1 .

The radiographic changes in SIJ (grade III and IV) were more frequent in LOAS pts than in COAS ( $<<0,005)$, as well as on the spine $(\mathrm{p}<0,005)$. The radiographic progression in the SIJ and the spine were more rapid in LOAS pts than in COAS pts, the difference was statistically significant $(\mathrm{p}<0,005)$.

\begin{tabular}{llll} 
Abstract SAT0028 Table 1 & \\
\hline LOAS & COAS & p \\
\hline Sacroiliitis grade I+II & $10(34.3 \%)$ & $20(69 \%)$ & $<0.005$ \\
Sacroiliitis grade III+IV & $19(65.5 \%)$ & $9(27.5 \%)$ & $<0.005$ \\
Spondylitis L + Th + C & $15(51.7 \%)$ & $3(10 / 3 \%)$ & $<0.005$ \\
\hline
\end{tabular}

Conclusion According to our experince the onset of ankylosing spondylitis is uncommon after 51-st yr; LOAS and COAS have similar clinical manifestations; LOAS had clinically more progressive course and rapid radiopraphic progression leading to severe changes in the SIJ and spine $(p<0,005)$. the possible explanation for the difference observed is a clinically asymptomatic or ?silent? ankylosing spondylitis in patients with late onset of disease.

\section{REFERENCE}

1 Caplanne D, Tubach F, Marie Le Parc J. Late onset spondyloarthropathy: Clinical and biologycal comparation with early onset patients. Ann Rheum Dis. 1997;56:176-9

\section{SAT0029 THE ROLE OF MICROFLORA IN ANKENT (ANKYLOSING ENTHESOPATHY) IN MICE}

${ }^{1} \mathrm{Z}$ Rehakova, ${ }^{1} \mathrm{~J}$ Sinkora, ${ }^{1} \mathrm{~T}$ Hrncir, ${ }^{1} \mathrm{R}$ Stepankova, ${ }^{2} \mathrm{~J}$ Capkova, ${ }^{3} \mathrm{P}$ Ivanyi. ${ }^{1}$ Immunology and Gnotobiology, Institute of Microbiology, Academy of Sciences of the Czech Republic, Novy Hradek; ${ }^{2}$ Institute of Molecular Genetics, Academy of Science; ${ }^{3}$ Immunogenetics, Institute of Clinical and Experimental Medicine, Prague, Czech Republic

10.1136/annrheumdis-2001.381

Background Murine ankylosing enthesopathy (ANKENT), an experimental model for human ankylosing spondylitis, is strongly dependent on the contact of ANKENT-prone mice (B10 or B10. BR genetic background) with microbes as no disease is observed under germfree (GF) conditions while about $20 \%$ of conventional (CV) males are afflicted.

The disease is almost exclusively restricted to male mice, It affects only ankle and tarsal joints. Next risk factor for ANKENT is haplotype. 
Objectives To confirm a hypothesis that ANKENT-triggering agents are intestinal bacteria to identify the ANKENT-triggering strains by technique of controlled association of GF mice.

Methods B10. BR males from a previously established GF colony were oligoassociated with a cocktail of anaerobic bacteria isolated from a diseased CV male. The mice were checked for ANKENT once a week. Lymphocyte phenotype in afflicted as well as healthy males was determined.

Results Oligoassociation with the selected cocktail of bacteria resulted in ANKENT in $>20 \%$ of ex-GF males, which corresponds to the situation seen under CV conditions and exceeds the ANKENT incidence in specific-pathogen-free mice.

Conclusion ANKENT-triggering agents are bacteria. The importance of viruses, protozoa and helmints in ANKENT onset can be excluded. Our findings strongly suggest that, similar to other spondylarthropathies, intestinal microflora has a inductive role in ANKENT pathogenesis.

Supported by grant GACR 310/00/1371.

\section{REFERENCE}

1 Rehakova, et al. Hum Immunol. 2000;61:555

\section{SAT0030 RELATIONSHIP BETWEEN DISEASE SEVERITY AND HLA- B27 AT TIME OF DIAGNOSIS IN ANKYLOSING SPONDYLITIS}

K Sivrioglu, M Aydogan, S Bayram, J Irdesel, S Kucukoglu, O Ozcan. Physical Medicine and Rehabilitation, Uludag University Medical Faculty, Bursa, Turkey

\subsection{6/annrheumdis-2001.382}

\section{Background}

Objectives This retrospective study was designed in order to evaluate the relationship between disease severity and HLA-B27 at time of diagnosis in ankylosing spondylitis (AS).

Methods Medical records of patients admitted to the outpatient clinic of Uludag University Medical Faculty, Department of Physical Medicine and Rehabilitation since 1988, who were diagnosed to have AS according to the 1966 New York Criteria were retrospectively reviewed. Forty-four patients were first diagnosed and had HLA-B27 evaluation. Further analysis was performed for this group which constituted the study population including sex, age at onset, disease duration until admission, HLA-B27 status, family history of AS, rheumatic symptoms, morning stiffness duration, presence of arthritis, sacroiliac tests, ESR $(\mathrm{mm} / \mathrm{hr})$, CRP (mg/dl), radiographic grade of sacroiliitis, and lumbar flexibility (assessed by Schober?s test), lumbar lateral flexion limitation, finger-to-floor distance, occiput-wall distance, chin-tomanibrium distance, chest expansion.

Results Out of the study population (11 female, 33 male; $\mathrm{n}=$ 44) with a mean age of $34.5 \pm 10.2$ years, 35 patients $(79.5 \%)$ were HLA-B27 $(+)$. Mean age of disease onset was $30.0 \pm 9.9$ years, and mean time of disease duration until diagnosis was $55.6 \pm 47.5$ months. Eight patients $(13.8 \%)$ had a positive family history, 9 (20.5\%) had heelpain, $5(11.4 \%)$ had chestpain, 42 $(95.5 \%)$ had backpain, and $3(6.8 \%)$ had systemic involvement at admission. Radiographic sacroiliitis was found as Grade: 2 in 15 patients, Grade: 3 in 16 patients, and Grade 4 in 13 patients.

Disease duration until admission was significantly less in HLA-B27 (+) patients compared to B27(-) ones ( $\mathrm{p}=0.027)$. Duration of morning stiffness was significantly higher $(\mathrm{p}=$ $0.050)$, and significantly more $\mathrm{B} 27(+)$ patients had positive sacroiliac tests $(\mathrm{p}=0.048)$. However, physical parameters such as lumbar lateral flexion and chest expansion was significantly better ( $\mathrm{p}=0.003$ and 0.018 , respectively) in B27 $(+)$ patients. No significant difference was observed in other clinical and physical parameters.

Conclusion Our results suggest that B-27(+) AS patients tend to admit earlier with more severe clinical symptoms and signs before the development of physical limitations.

\section{SAT0031 FINE EPITOPE MAPPING OF IMMUNODOMINANT PEPTIDE EPITOPES BY AFFINITY MATRIX TECHNOLOGY USING YERSINIA-HSP60-SPECIFIC SYNOVIAL CD4 ${ }^{+} \mathrm{T}^{-}$ CELLS IN REACTIVE ARTHRITIS (REA) PATIENTS}

${ }^{1} \mathrm{~A}$ Thiel, ${ }^{2} \mathrm{P}$ Wu, ${ }^{1} \mathrm{D}$ Stauch, ${ }^{2} \mathrm{M}$ Rudwaleit, ${ }^{1} \mathrm{~A}$ Radbruch, ${ }^{2} \mathrm{~J}$ Sieper. ${ }^{1}$ Rheumatology, German Rheumatism Research Center; ${ }^{2}$ Rheumatology, Benjamin Franklin University Hospital, Berlin, Germany

\subsection{6/annrheumdis-2001.383}

Background A T cell response to persitent bacterial antigen is present in patients with reactive arthritis (ReA). A better characterisation of this response might lead to new treatments.

Objectives To identify immundominant Yer-hsp60-derived CD4 T cell epitopes in Yersinia-induced reactive arthritis (ReA).

Methods In two patients with Yersinia-induced ReA synovial fluid (SF) $\mathrm{T}$ cell response were first investigated after in vitro stimulation with the Yersinia-derived protein hsp60. Fixed cells were stained with antibodies against CD4, CD8, CD69 and against the cytokine IFNgamma; Patients with reacting $\mathrm{CD} 4^{+}$ Th cells were retested and live IFNgamma-secreting cells were isolated with the affinity matrix technology after short term stimulation with Yer-hsp60. Cells were expanded within 2 to 5 weeks and retested with overlapping 18 mer peptides from the Yer-hsp60 protein performing cytometric analysis of fixed cells after short term stimulation with peptided pulsed autologous PBMCs.

Results Live antigen-specific IFNgamma;-secreting $\mathrm{CD}^{+}{ }^{+} \mathrm{T}$ cells were enriched to a purity of 80 to $90 \%$. After two weeks in vitro expansion still $80 \%$ of the short-term cultivated $\mathrm{T}$ cells reacted with IFNgamma-production upon Yer-hsp60 stimulation, while reaction upon stimulation with a irrelevant protein was below 1\%. T cells were further expanded antigen-specifically for 3 weeks and their fine specificity was further mapped to one peptide in each patient (AA 139-156 and AA 7-30 of Yer-hsp60/ GroEL). Tese peptides was also recognised by the patient's $\mathrm{CD} 4^{+}$T cells when whole blood or synovial fluid was stimulated for $6 \mathrm{~h}$.

Conclusion This approach allows a sensitive and fast epitope mapping of immunodominant epitopes possibly involved in the pathogenesis of ReA.

\section{SAT0032 PREVALENCE OF UVEITIS AND SJÖGREN'S SYNDROME (SS) IN PORTUGUESE PATIENTS WITH ANKYLOSING SPONDYLITIS}

1f Figueirinhas, 'f Vaz Patto, 'MM Silva, ${ }^{2} \mathrm{~J}$ Gil Forte, ${ }^{2} \mathrm{LN}$ Ferraz de Oliveira. ${ }^{1}$ Rheumatology, Portuguese Institute of Rheumatology; ${ }^{2}$ Ophtalmology, Hospital Egas Moniz, Lisbon, Portugal

10.1136/annrheumdis-2001.384

Background

Objectives

- To evaluate the prevalence of uveitis, SS and Sicca syndrome $(\mathrm{SicS})$ in patients with AS. 